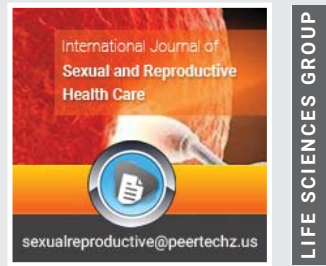

\title{
Sexual fantasies: The boundary between physiology and psychopathology. Clinical evidence
}

\section{Giulio Perrotta*}

Psychologist sp.ing in Strategic Psychotherapy, Forensic Criminologist, Legal Advisor sp.ed SSPL, Researcher, Essayist, Institute for the study of psychotherapies - ISP, Via San Martino della Battaglia

Received: 09 April, 2021

Accepted: 16 June, 2021

Published: 17 June, 2021

*Corresponding author: Dr. Giulio Perrotta, Psychologist sp.ing in Strategic Psychotherapy, Forensic Criminologist, Legal Advisor sp.ed SSPL, Researcher, Essayist, Institute for the study of psychotherapies - ISP, Via San Martino della Battaglia no. 31,00185 , Rome, Italy,

E-mail:info@giulioperrotta.com

ORCID: https://orcid.org/0000-0003-4560-584X

Keywords: Dysfunctional sexual behaviour; Paraphilias; Sexual fantasies; PICl-1; PSM-1; MMPI-II

https://www.peertechzpublications.com

\section{Check for updates} no. 31,00185 , Rome, Italy

\section{Abstract}

Purpose: In order to study in depth the paraphiliac universe of the patient, avoiding diagnostic errors in terms of sexuality, sexual fantasies and disorders codified by the DSM-V, this research work focused on the importance of the exact identification of relevant sexual behaviours, in order to facilitate the relationship with the patient and the therapeutic pathway.

Methods: Clinical interview with administration of the "Perrotta Integrative Clinica Interview” (PICl-1) and "Perrotta Individual Sexual Matrix Questionnaire” (PSM-1).

Results: Once the questionnaire was completed, it was tested on a population sample of 122 subjects (69 male and 53 female), demonstrating diagnostic error in $22.13 \%$ of cases ( 27 total) and in particular in the two youngest groups of both sexes (14-24 years and $25-35$ years), reaching $37 \%$ error in females and $40.7 \%$ in males.

Conclusions: The present research work has laid the foundations for a more accurate and detailed investigation of the diagnostic universe linked to paraphiliac disorder, demonstrating that: 1) At the diagnostic stage, it is always possible to commit an interpretative error by mistaking a simple paraphilia for paraphiliac disorder, also taking into account the psychological disorders present in comorbidity. 2) The MMPI-II identifies some characteristics that can be traced back to paraphiliac disorder and other related personality disorders but does not specify in detail the paraphiliac universe of the patient and therefore the exact therapeutic intervention to be carried out in psychotherapy. 3) The PICl-1TA fully absorbs the results of the MMPI-II and notes its critical aspects, such as the absence of the indications of the specific personality traits, useful in the diagnostic and therapeutic phases, without however listing in detail the paraphiliac universe of the patient. 4) The PSM-1, if associated with the PICI-1TA, allows to identify the primary disorder, the characterizing secondary traits and the whole paraphiliac universe of the patient, for the purposes of the clinical diagnostic profile and of the specific targeted therapeutic intervention to be carried out, giving also information about the medical history and other possible associated sexual disorders. 5) The PSM-1 was able to detect, on a sample of population n. 122, n. 27 (16 male and 11 female) diagnostic errors (22.13\%) in the phase of centering of the patient, depowering the diagnosis of paraphiliac disorder to simple paraphilia to be managed in a framework more deprived of judgment. 6) The PSM-1, unlike other psychosexual tests and questionnaires, allows to analyse at the same time with precision the following aspects: a) personal and family psychophysical history; b) information about orientation, gender and related sexual disorders; c) the paraphiliac universe, with specific indications of the object/content of individual behaviours; $d$ ) the psychodynamic profile of the patient, on the basis of his disorder (if present) or of the simple behavioural manifestation of a paraphiliac matrix; e) categorisation by intensity, severity and content. 7) The present research work has therefore demonstrated the reliability of the psychodiagnostic instrument, also noting that the highest percentage of diagnostic error on the subject of sexual behaviour is present in both males and females in the 25-35 age band, followed by the $14-24$ age band, for an overall total of $40.7 \%$ in males and $37 \%$ in females. It would appear that diagnostic errors are less frequent in the older and more mature age groups. In relation then to the MMPI-II and the PICl-1 it proved particularly functional with the latter, in order to proceed to the therapeutic contract with the patient and therefore to the implementation of the necessary strategies in support, assistance and therapy. 


\section{Contents of the manuscript}

\section{Foreword}

In clinical practice, one often encounters patients (and professionals) who do not clearly distinguish between 'sexual fantasies' and 'sexual perversions' and thus the boundary between physiological and pathological conditions.

In addition, it often happens that the sexual theme is a source of embarrassment for the patient who, in the first sessions, also to discover affinity with the therapist, 'avoids' telling in detail his fantasies and paraphiliac tendencies, especially with regard to intensity, frequency and ability to interfere with the normal conduct of life.

On the necessity to have immediately a complete and detailed picture of the clinical position of the patient, during the development of the first cycle of sessions (those dedicated to the cognitive and informative interview, for the construction of the detailed anamnesis), the writer saw the opportunity and the necessity to construct a questionnaire that was suitable both for the drawing up of the anamnesis and for the deep knowledge of the paraphiliac tissue, concluding the same with a test of n. 10 items with binary answers (YES/NO) and on a likert scale $1-5$ (positivity > 20/50), able to give an immediate perception to the therapist of the seriousness and the importance of the disorder found.

However, before delving into the proposed questionnaire, called PSM-1, it is necessary to take a theoretical look at sexual fantasies and paraphilias.

\section{Introduction: The distinction between sexual fantasies and paraphilias}

In common jargon, 'sexual fantasies' are often confused with 'sexual perversions' because of their social and moralistic connotations; however, there are profound differences, also because of their pathological component [1].

The first step, therefore, concerns the specific definition of the individual lexical terms used, starting from the general concept of 'fantasy' [2] from which everything originates. A fantasy is a situation imagined by an individual in relation to certain desires, needs, requirements or expectations, which condition its content, ranging from realistic situations (for example, obtaining an award after a professional achievement) to the completely improbable (for example, performing a normally unusual but extremely exciting sexual act such as an orgy or sex shared with two people) and science fiction (for example, having superpowers or becoming rich and powerful) [3]. Thus, on the basis of these (entirely subjective) elements, fantasy can be classified as 'functional' or 'dysfunctional' [1]: In the first case, fantasy acts as a simple vehicle of thought to relieve anxiety or inner tension arising from a fear or frustration (effectively providing compensation); In the second case, fantasy becomes pervasive and disturbing (depending also on the level of adherence to the reality plane) [4] until it becomes a real psychopathological component of a disorder in its own right, such as obsessive disorder [5], paranoid disorder
[6], delusional disorder [6], psychotic [7] and dissociative disorders [8], bipolarity [9] and personality disorders [1011]. A dysfunctional example is provided by Vaillant himself in his study on defence mechanisms [12] when, for example, he mentions the immature defence in narcissistic disorder underlining how the extreme use of fantasy is a common and symptomatic trait.

In classical psychodynamics [3,13-21], the terms 'fantasy' and 'unconscious fantasy' are used extensively, although they mean different things to different authors, a situation that has given rise to many misunderstandings in scientific discussions. In particular, starting from the (biological) concept theorised by S. Freud, Klein introduces a much broader meaning of the term 'fantasy' which ends up radically changing its meaning. In this new meaning (for which $\mathrm{S}$. Isaacs proposed using the English term 'phantasy' as opposed to 'fantasy') fantasies as 'primary content of unconscious mental processes' are active from the beginning of life, underlie every mental process and accompany all mental activities. In S. Freud's formulation, in fact, fantasy was a rather late function which implied that the principle of reality had been established (just as hallucinatory gratification of desire, which was a sort of precursor, represented an illusory form of internal satisfaction and therefore intervened only in the absence of external gratification); for Klein, on the other hand, unconscious fantasy is not constituted in opposition to external reality, but is a continuous, ubiquitous activity, a sort of constant unconscious background which characterises mental life from birth. It takes the form of a continuous and kaleidoscopic flow of mental forms that underlie experience and, in some way, organise it, meaning both the experience the child has of his own body, through the sensations linked to its organs and their functioning, and that relating to the external environment. This extension of the meaning of the term 'fantasy', which for some critics is excessive because it would make fantasy coincide with every manifestation of mental life, describes primitive mental functioning as a continuous and variously articulated flow of psychosomatic fantasies that transforms sensory experience into something mental. The unconscious fantasy is the retranscription or translation (representation) of sensations, perceptions, etc. to the mental level. It is defined, in fact, as 'the mental corollary, the psychic representative of instinct. There is no impulse, or drive, or instinctual response that is not experienced as an unconscious fantasy'. Desire, whether libidinal or destructive, is experienced as a specific fantasy that 'leads the child to represent to himself what in detail he wishes to do to the object'. On the other hand, as another author points out, the habit of translating the Freudian term "Trieb" into English with the term "instinct" instead of "drive" leads to confusion: "if in fact Instia were to be used here by Isaacs in its more properly biological meaning, it would follow that unconscious fantasy and drive would be exactly the same thing, since drive is considered by Freud as the psychic representative of the biological". If, on the other hand, instinct is used by Isaacs instead of drive and designates the drive, the latter, which is the psychic representative of the biological, expresses itself, manifests itself, represents itself through the unconscious fantasy. Freud, in 1915, had already posed the 
problem that the drive should have a psychic representative in the form of 'an idea', making the unconscious fantasy the psychic representative of the drive allows us to grasp its presence in the mind in concrete terms. The unconscious fantasy is defined first of all in relation to the body, both as the mental expression of the drive and therefore of the id, and through the description of how the first fantasies arise from the sensations of the body, already from 'the massive and varied stimuli of birth and of the first inhalation and exhalation of air'. The definition of the fantasy as a 'psychic representative of the drive', if on the one hand is in continuity with Freud's thought, noting the need to maintain a link between psychic manifestations and the body and its needs, on the other hand, freeing itself from the more traditional concepts of investment and energy charges, reinterprets the link with the body in a new and original way in the light of important and innovative clinical and observational insights into early mental life, in which the role of sensoriality appears in the foreground. Isaacs' exemplifications aim to describe the massive and concrete presence of this somatic sensory level in the child's psychic life with the intention of grasping the passage from the sensory level to the more mental level of image and representation. In fantasy, however, this passage has already taken place. The concern, in continuity with Freud's need to reiterate the mental character of unconscious phenomena, seems to be to ensure that these first manifestations also have a mental or psychic character, without underestimating the sensory-body component. Unconscious fantasies, as mental representations of those somatic events that include drives, 'derive from physical sensations interpreted as relations with the objects that cause these sensations', are born from sensations and affects, long before the development of language, and, probably, at first without visual or plastic images. The infant, for Isaacs, does not experience a dichotomy between body and mind but 'a single, undifferentiated experience' in which body and mind are not yet distinct and separate. "These sensations (and images) are a bodily experience which at first correlates very inadequately with the external and spatial object; the data which come from the coenesthetic, genital and visceral sensations do not. They convey the fantasy that has a concrete bodily quality, a 'proper me', experienced in the body. At this level it is difficult, if not impossible, to distinguish images from real sensations and external perceptions. The skin is not felt at all as an element delimiting external reality from internal reality. Primitive fantasies are thus experienced as both somatic and mental phenomena: both the fantastic objects and the satisfaction they bring are experienced as physical occurrences Isaacs' formulation condenses together both the link with the body, through primitive sensoriality, and the link with the object, which is always present in fantasy, underlining its intensely affective colouring. Physical experiences are experienced and interpreted as fantastic object relations, with intense emotional significance (and vice versa, fantasies are so closely linked to the somatic sphere that they can affect physical functioning). Primary fantasies are determined by the logic of emotions, are 'imbued with sensations and affects' and express an 'affective interpretation' of bodily sensations. Fantasies always concern a relationship between the self and the object, since 'the relationship with the object is inherent in the character and direction of the impulse itself and in the affects connected with it'. But the object is no longer the abstract goal of instinct but a concrete and affective presence in the child's mind, whose fantasy expresses the innate and ineliminable intentionality towards objects. In fantasy, the child does something to an object or undergoes an action from it. Fantasy, therefore, however narcissistic it may appear, always contains a relationality. The relationship between unconscious fantasy and external reality is more complex. In Isaacs' formulation, fantasies 'express first of all an internal and subjective reality, although from the beginning they are connected with a real, albeit narrow and limited, experience of external reality'. Both fantasy and evidence of reality are in fact present from the earliest days of life. Sensations, no matter how selectively emphasised by the pressure of affect, put the mind in touch with both external reality and impulses and desires. "'From a certain point onwards perceptions from external reality begin to influence mental processes; thus early bodily experiences and external events gradually become interwoven into the web of fantasy'. Fantasies are connected not only to drives, but also to defences, and underlie all the mechanisms of mental functioning: what we define abstractly as a mechanism is experienced concretely by the subject in terms of fantasies felt to be real. The unconscious fantasy has extreme concreteness and reality, it is real in the experience of the subject: it is a real mental function, which has real effects, not only in the internal world, but also in the external world, in the bodily development and behaviour of the subject and from there in the mind and body of other people. This aspect, together with the constant and continuous interaction with the object, both internal and external, makes the unconscious fantasy a relational psychic phenomenon; the unconscious fantasy not only can be expressed and communicated through the body, but also has real effects on the interaction with the other, producing relevant changes in the mind and body of the other. In the introduction to the methodological principles of direct observation, Isaacs stresses the importance of observing the context of the behaviour studied, meaning by context 'the specific social and emotional situation'. Only 'attention to precise details captured in a global situation can reveal the meaning of a behaviour', which must then be inserted, according to the principle of genetic continuity, into the subject's previous history. Being interwoven with intense bodily sensations and emotionally invested by affections makes the unconscious fantasies vivid and real and contributes to giving them that concrete and omnipotent character that will also characterise their subsequent functioning. While more evolved forms of representation and thought develop, primitive fantasies remain active in the unconscious life of the adult individual, constituting a kind of split enclave that exists alongside and below the more evolved functioning. This aspect of concreteness and deep connection with the somatic radically differentiates unconscious fantasies from the world of representations that are images of the self and objects in the mind. In the unconscious fantasy of an internal object 'because of the omnipotence of the primitive fantasy the individual experiences a real object felt to be physically present within the 
body and usually identified with a part of the body. Representations and images, on the other hand, are mental contents which lack that sense of concreteness; they are recognised as representations'. The unconscious fantasies of the internal object world coexist with representations and give them 'colour, energy, passion and meaning'; they would thus correspond to Sandler's concept of affective investment of representations. As Spillius points out, the theme of unconscious fantasy, although clinically much used in the Kleinian current, has not been developed in subsequent theoretical contributions by authors of this school, with the exception of some work by Segal, in addition to taking up the formulations of Isaacs, better specifies the relationship between unconscious fantasy and higher mental functioning, underlining the elements of continuity between unconscious fantasy and thought: both perform, in different phases of the child's life, an analogous function that consists in allowing the Ego to bear the tension without an immediate motor discharge. Imagination is therefore a sort of precursor of thought, with which it maintains complex relationships even later on. "Thought, in fact, is not only hindered by fantasy but is also based on it and produced by it. The origins of thought are said to lie in a process of verifying fantasy in reality. Compared to Isaacs' approach, Segal gives much more prominence to the function of the reality check, probably influenced in this by Bion's thought, to which she makes explicit reference by proposing an overlapping of the concept of unconscious fantasy with that of pre-conception. "Unconscious fantasies are a series of hypotheses that can be put to the test of reality". Both in the constitution and in the subsequent development of fantasies, reality plays an important role: in fact, the author insists on the continuous exchange between fantasy and reality that during growth influence and modify each other, in a "constant struggle" between the omnipotence of fantasy and the impact of reality. The reality check, present in some way from the beginning of life, plays a central role in this: mental life will be crucially influenced by the ability to recognise and tolerate the discrepancy between omnipotent fantasies and reality. Developing lsaacs' assertions about the relationship between defence mechanisms and unconscious fantasies Segal emphasises how the dynamics of unconscious fantasies determine the formation of mental structure and the basic character of personality. "The structure of the personality is to a great extent determined by the most permanent of the fantasies which the ego has of itself and of the objects it contains". It is precisely this connection between structures and unconscious fantasies that makes it possible to influence the structure of the ego and superego through analysis [22].

Sexual or 'erotic fantasies' are all those mental images or thought patterns, conscious or unconscious, that may appear in the imagination during sexual intercourse or that one creates on purpose (through a thought or memory) to produce a situation of sexual arousal. Anything that can give rise to arousal can also give rise to a fantasy. Sexual fantasy resides entirely in a person's mind, it can be activated autonomously through various means, for example by a text of erotic literature, by watching a pornographic film or by other types of images, such as photographs and representations of erotic art. Sexual fantasies are an almost universal phenomenon; however, due to the extremely transgressive and taboo nature of some of them, they are self-imposed: some people find it more appropriate to try to realise their fantasies through sexual role-play. A fantasy can be a positive or negative experience, or even both at the same time; it can be a response to a past experience and can come to influence one's sexual behaviour in the future. Sexual fantasy scenarios vary greatly from one individual to another, influenced as they are by personal desires and experiences, and are often used to escape the real sexual restrictions or condition of sexual abstinence in which one may find oneself. Unlike women, men tend to focus more on a specific area of the body, are more likely to concentrate on the physical stimulation of one area and do not see themselves as a 'whole': indeed, men's fantasies tend to focus on explicit visual images and anatomical details, while women's tend to contain a greater degree of emotional or romantic connection; men then, whether heterosexual or homosexual, are more interested in various types of sexual stimulation and casual intercourse. Another difference between men's and women's fantasies is that men are more likely to fantasize about threesome and orgy. The sexes also differ in terms of their imagery of domination-submission situations, with women much more likely than men to fantasize about being in a submissive or slave position (BDSM). Finally, women prefer to include known people in their fantasies rather than total strangers [23-25].

So far, no critical terminology. The problem begins to emerge when one tries to define the concept of 'perversion' or 'deviant sexual fantasy', understood as a (markedly) deviant attitude (compared to what one would expect from the commonly recognised concept of 'normality') that is realised in the conception and pursuit of behaviour that is distorted from common sense. This term, therefore, is used for behaviour that is opposed to orthodoxy and normality. Usually, 'perversion' is used as a synonym for deviance, even if, more precisely, the latter represents a violation of recognised social norms; for this reason, in order not to run into critical judgments or moralistic evaluations, for some decades now, after the intervention in the 1970 s by the psychiatrist Stoller, the term 'perversion' has been replaced by the term 'paraphilia' $[1,2]$.

In the Freudian model, 'perversion' (the term paraphilia had not yet been used) is described as part of the drive and an essential component of psychosexual development. In the book "Three Essays on Sexual Theory" (1905), Freud classifies the various pathological forms of sexual perversion into aberrations concerning the goal (exhibitionism, voyeurism, sadism and masochism) and aberrations concerning the sexual object (homosexuality, paedophilia, zoophilia). It also describes the different partial drives, corresponding to different erogenous zones, which will later (at the end of the psychosexual development process) submit to genital primacy. The failure of this process determines a conflict that can be of two types: neurotic or perverse. Hence neurosis becomes the negative of perversion. For S. Freud, perversion is part of normal psychosexual development, but from puberty onwards it can take on a pathological form depending on how far the new sexual goal (perversion) departs from normality. S. Freud, 
has repeatedly shown that an important role in the formation of perverse symptoms, are the mechanisms of libidinal fixation and regression, in determining the achievement of sexual pleasure through partial instincts with partial objects. The physiological feature of infantile sexual life is autoeroticism, which is used to give satisfaction to partial and independent drives. The end result of affective development is reflected in adult sexual life, where pleasure is achieved through the satisfaction of genital drives by the presence of an external sexual object. Constitutional (internal) or environmental (external) factors can influence the normal development of infantile sexual life, and allow each stage reached to become a point of libidinal fixation. The individual, being strongly inclined after puberty to regress to the stage of fixation, will be prevented from achieving the unification of the partial instincts and the activities with which to satisfy them. The appearance of perverse symptoms in adulthood will be one of the effects produced by the altered process of psychosexual growth. In perverts, the existence of a constitutional disposition that is very surrendered to the satisfaction of polyform perverse sexual instincts (polymorphously perverse disposition) is one of the internal causes responsible for the deviation in the development of sexuality. These are subjects, inclined even in adulthood to seek pleasure through the satisfaction of partial impulses, showing little resistance to sexual excesses normally imposed by morals and ethics. In the years of the sexual revolution, along with Stoller, Khan, an English psychoanalyst, observed that the quality of the mother-child relationship, experienced from early childhood is one of the environmental elements that takes on weight in negatively conditioning psychosexual development, just as Klein and Winnicott did a few years earlier. Khan, still strongly tied to his psychological current, starting from D. Winnicott's concept of "transitional object" and from the role played by S. Freud's eroticization of partial sexual drives, formulates the concept of "composite internal object" to explain the internal reality of the pervert derived from the primary object relationship, from which the future mode of entering into a relationship with the objects of his existence springs. Thus, the composite internal object plays a role normally assumed by the transitional object in the formation of the individual's intrapsychic world and his way of coming into contact with external reality. The transitional object is something external, and it remains external as an entity in itself, even though it is subject to the omnipotent psychic imagination of infantile experience. This primitive stage of development is made possible by the mother's special ability to adapt to the infant's needs, allowing him the illusion that what he creates really exists. In the reality experienced by a potential pervert, all these factors are reversed. He has to deal with unadapted maternal care from the very beginning. The mother devotes herself intensively to the care of the child, but in an impersonal way. The child is regarded by the mother as a "thing of her own making", not a developing person with his or her own rights. As a result of this maternal behaviour, the child begins very prematurely to perceive that what the mother is, who invests him or her with all her affection, is not him or her as a whole person, but only aspects of him or her (the ego functions and the bodily ego). In the following period, the child internalises the self as a "thing" created by the mother.
These experiences deform the child's ego and prevent it from developing in an integrated way. Khan, observes that the perverse Ego will be the result of a collage: the development of the functions of the Ego and the instinctual one proceed parallel and distinctly in the absence of the investment of the experiential emotional part. This type of subject will relate to others, not only to satisfy their own drive needs, but not to love and be loved, but to find a type of participation that will transform what is extraneous to the Ego into something connected to the Ego. Because of the primary delusion experienced, in the pervert the relationship with the other will always be aimed at seeking a state of illusory unity, in which the other understands, pities, and satisfies all the needs of his own ego and all his instinctual tensions. Thus object dependence is translated into forcing the object to adapt itself. The other will be someone who, according to the intrapsychic reality of the perverse person, will have to be acquiescent to the point of being reduced to an inanimate thing and achieve a real identification with him. Hence the pervert's need to create the composite internal object in place of a transitional object. The internal composite object, unlike the transitional one, is something intrapsychic, and from this derives a continuous internal pressure that must be externalized, with the sexual event [3,26-28].

To sum up, then, it can be said that the essence of perversion, clinically understood, is not so much the act or fantasy itself as the relationship of the person with it, based on his or her own personality organisation. Central to perversion proper are the rigidity of acts and fantasies, their eroticization, the splitting of the ego, the loss of the perception of one's own body as part of the self, the idealization of perverse defences and the constant attempt to seduce the healthy parts of the personality and to transform others, including the therapist if any, into objects of an internal representation [1,3].

Therefore, in accordance with the scientific trend of recent decades, we should prefer to use the neutral term "paraphilia" to the more moralistic and critical term "perversion", defining it as the erotic drive characterised by intense and recurrent fantasies or impulses involving specific activities or situations involving people, objects or animals and involving discomfort, guilt and shame for those who enact them. The fifth edition of the Diagnostic and Statistical Manual of Mental Disorders, edited by the American Psychiatric Association in 2013 [29] introduced an important change on the subject of paraphilia/ paraphilic behaviour: "paraphilias" are considered all those atypical sexual behaviours for which the subject feels a strong and persistent erotic-sexual arousal. This erotic condition is experienced in perfect egosyntony. When, on the other hand, paraphilic behaviour becomes a form of addiction and the subject feels a certain interpersonal discomfort (egodystonia), then it is useful to introduce the concept of "Paraphilic Disorder" [30].

\section{The aetiology of the paraphiliac phenomenon and neural correlates}

In the scientific literature, the aetiological issue in paraphilias is much debated, as there is still no definitive 
confirmation. As for many pathological conditions, the most accredited theory appears to be the multifactorial one, among the following main hypotheses [31].

Early emotional, physical or sexual trauma interfered with normal psychosexual development.

The normal pattern of arousal is replaced by another pattern, sometimes through early exposure to highly charged sexual experiences that reinforce the subject's experience of sexual pleasure.

The sexual arousal pattern often acquires symbolic and conditioning objects (e.g., a fetish symbolises the object of sexual arousal but may be chosen because it has been randomly associated with sexual curiosity, desire, and arousal).

Neurobiological alterations of certain structures; however, it is not clear whether the reinforcement of the dysfunctional behaviour causes the establishment of paraphilia and therefore structural and functional changes in the brain areas or rather it is the latter hypothesis that causes the establishment of paraphilia. In the writer's opinion, the most accredited hypothesis is the first one.

Several scientific studies claim that the brain is a plastic organ and that the frontal cortex, the seat of the executive and cognitive functions, has greater plasticity. This cortex is very important because it regulates emotional states and is responsible for decision-making and planning. In addition to being the centre of willpower, this cortex is linked to a myriad of functions that are considered particularly developed in primates and, in particular, in humans. It is central to the 'topdown' cognitive control mechanism, inhibition, emotional regulation and learning. This cortex is very important because it coordinates the functions of many cerebral areas and thus links information coming from the limbic regions and other parts of the organism. In addition, certain brain structures such as the hippocampus (responsible for memory) and the amygdala (involved in the processes of attack and escape and the response to fear) help to achieve this emotional balance. Studies using functional magnetic resonance imaging (FMRI) show that some abusers show greater activation of the limbic system (involved in emotions that determine the individual's behaviour) and less activation of the frontal cortex (important in regulating and inhibiting emotions) in response to aggressive stimuli. These results suggest, although it has not yet been demonstrated, that a hyperactivation of the limbic system combined with a hypoactivation of the prefrontal cortex may lead individuals to commit violent and aggressive acts. Hormones also play a key role in aggression, such as the relationship between testosterone and the subjective experience of anger, and anger was associated in the final results with an increase in the hormone testosterone. Indeed, it is known that testosterone, a steroid hormone secreted by the hypothalamicpituitary-gonadal axis, can promote aggressive and dominant behaviour in males [32-35].

\section{Clinical hypotheses}

According to the theoretical model underlying the MMPI-II and the DSM-V, we know that Paraphiliac Disorder consists of a disorder in which the subject is affected by one or more paraphilias. In particular, to be distinguished from functional sexual behaviour, they must have the following characteristics: [1,36-39].

Presence of sexually arousing fantasies, impulses and behaviour, with recurrence, persistence, intensity (for at least 6 months) and with constant and progressive frequency.

Marked discomfort, compulsivity or difficulty in living the circumstance calmly.

Unusual, bizarre and/or excessive sexual activity, usually with children, non-consensual persons, objects or nonhuman beings, or with the intention of practising or receiving humiliation, domination or submission.

Heightened emotionality, frenzy, manic and/or dysfunctional anxiety $[40,41]$ in the performance of the sexual fantasy, impulse, or behaviour.

Profound guilt, shame, fear, anxiety, social disapproval or other negative judgmental feelings at the time of fantasy or fantasy actualization.

Interference with other spheres of life (work, friendship, social, family)

More or less marked exclusivity of the behaviour causing sexual arousal.

However, if the unusual, unusual, or bizarre sexual behaviour is not characterised by the above-mentioned features (and the reality plane is intact), one cannot speak of a paraphilic disorder. The diagnosis of Paraphilic Disorder should be reserved exclusively for individuals who meet both criteria (A and B) of the DSM-V; otherwise, one will speak of "paraphilia" but not of "disorder" $[1,30]$.

There are dozens of paraphilias and they are generally classified according to the 'act' they replace or the 'object' towards which they are directed: in the part of the act there is a substitution of coitus or sexual activity with practices of another type, while in the part of the object there is a substitution of the normative object or a shift of the goal (in practice, the normative object is the sexual partner while the goal is represented by the achievement of sexual pleasure) $[1,36,37]$.

A further subdivision concerns the 'sensory channel' that is stimulated: the five senses. And in particular $[1,38]$.

a) the visual channel, whereby sexual arousal is sought in the exhibition of the body or parts of it (exhibitionism), in the observation of other subjects engaged in sexual activity (voyeurism, mixoscopy) or of physiological bodily functions (coprophilia, urophilia);

b) the acoustic/verbal channel, whereby arousal is obtained by practising bad language, listening to or uttering scurrilous or vulgar words relating to sexuality (telephone scatology, coprolalia, pornolalia, mixacusi). 
c) the olfactory channel, since there are neurophysiological connections between the vomero-nasal organ and certain areas of the brain, such as the limbic system (emotional) and the BNST nucleus (nucleus of the stria terminalis) and therefore sexual arousal is given by the perception of odours, even unpleasant ones, such as urine, faeces, flatulence (flatulophilia), sweat (ospressiophilia), this can be connected to the pheromones excreted with these substances;

d) the gustatory channel, whereby sexual arousal is pursued through the ingestion/irroration of bodily excretions (coprophagia, spermatophagia, pissing).

e) the tactile channel, where sexual pleasure is given by the practice of unusual bodily activities: stuffing (penetration with objects), beating, spanking, chlismaphilia (enema practice), nasophilia, rhinolagnia, urethrolagnia (stimulation of parts of the body that are not classically erogenous, such as the nostrils or the urethra).

The new nomenclature of paraphilic disorders described by the DSM-V is still organised, in clinical practice, within two different groups $[1,39]$.

a) "Predilection for unusual activities", where there are all those disorders that represent a particular deviation from the courtship phases such as frotteuristic disorder, voyeuristic disorder and exhibitionistic disorder, but also those "algolagnic" disorders that involve pain and suffering such as sexual masochism disorder and sexual sadism disorder;

b) "Predisposition for atypicality of sexual object", where interest and attention are directed towards other human beings, but also where the subject experiences intense and persistent attention directed elsewhere, as in fetishistic disorder and transvestite disorder.

Eight major forms of sexual perversion are clinically recognised $[1,36,45]$.

1. Exhibitionism: Sexual arousal through exposure of one's own genitals, often during masturbatory activities, in front of an uninvited stranger.

2. Fetishism: sexual arousal through the use of inanimate objects, such as women's clothing; often the subject achieves sexual pleasure through onanistic practices, while wearing, rubbing and smelling the fetish. He may also ask his partner to use it during sexual encounters.

3. Frotteurism: Sexual arousal obtained by touching or rubbing oneself against an unwilling person, an activity often carried out in crowded public places or on means of transport.

4. Paedophilia: sexual urges and activities towards children under the age of $12 / 13$, with the variant Pederasty for adolescents between 12/13 and 16/18.
5. Masochism: deriving sexual enjoyment from being subjected to physical and psychological suffering and humiliation by others.

6. Sadism: Sexual arousal derived from real and unsimulated acts involving the infliction of humiliation, beatings or suffering on a partner.

7. Cross-dressing fetishism: sexual impulses provoked by dressing up in clothes of the opposite sex; this category should not be confused with transsexualism, which is an outcome of gender identity disorder and is therefore not a paraphilia [46].

8. Voyeurism: sexual pleasure derived from spying on unsuspecting people while they are naked, in intimacy, or during their sexual relations; this condition should be distinguished from troilism, which consists in deriving sexual arousal from openly observing other people having sex).

Among the many rarer sexual perversions (paraphilias), we can mention zoophilia (sexual practices with animals), necrophilia (erotic investment in macabre scenes, with funeral rituals, and in some cases even sexual union with corpses), coprolalia or telephone scatology (arousal obtained by uttering obscene phrases on the telephone), partialism (sexual attention focused exclusively on one part of the body), coprophilia (drawing sexual arousal from faeces), urophilia or pissing (drawing sexual arousal from urine), cuckolding (shared betrayal) and chlismaphilia (use of an enema in erotic activities) $[36,48]$.

Homosexuality [49] and bisexuality [50], which were also traditionally considered forms of paraphilia, deserve a separate discussion. Subsequently, passing through egosyntonic and egodystonic hypotheses, it was decided to no longer consider them as a disorder but as real orientations, independent of heterosexuality. However, although this is not the ideal forum, it is worth mentioning the research on neurobiological findings on the subject of homosexuality and bisexuality, which also leaves open the psychopathological hypotheses, especially in relation to the fact that these new orientations are always connected in the anamnestic history to psychophysical traumas of the analysed subjects [51,52].

Finally, according to the theoretical model underlying PICI-1 [42-44], we know that Paraphiliac Disorder is a disorder common to all ages of development (precisely because it depends on a dysfunction of the normal process) and that it is always linked to a specific personality disorder (more present and marked in adolescents and adults).

As "paraphilia" is the starting point of this research work, it was decided to use the "Perrotta Individual Sexual Matrix Questionnaire" (PSM-1) [53].

\section{Practical application of PSM-1. Sample research}

The selected population sample is 122 participants, divided as follows: 69 males and 53 females. 
The selected setting, taking into account the protracted pandemic period (already in progress since the beginning of the present research), is the online platform via Skype and Videocall Whatsapp, both for the clinical interview and for the administration.

The present research work was carried out from April 2020 to December 2020.

All participants were guaranteed anonymity and for persons under 18 years of age, specific authorisation has been requested from their parents or guardians recognised by the Court.

The selected population sample is divided as follows:

\begin{tabular}{|c|c|c|}
\hline $\begin{array}{c}\text { Gender of the sample } \\
\text { Population }\end{array}$ & Bunds of Age & Sample Number \\
\hline Male & $14-24$ & 17 \\
\hline Male & $25-35$ & 27 \\
\hline Male & $36-46$ & 10 \\
\hline Male & $47-57$ & 8 \\
\hline Male & $58-68$ & 4 \\
\hline Male & $69-79$ & 3 \\
\hline Female & $14-24$ & 17 \\
\hline Female & $25-35$ & 20 \\
\hline Female & $36-46$ & 10 \\
\hline Female & $47-57$ & 3 \\
\hline Female & $58-68$ & 2 \\
\hline Female & $69-79$ & 1 \\
\hline
\end{tabular}

Once the population sample had been selected, which met the required requirements (age between 14 and 79 years, confirmed psychopathological diagnosis (paraphiliac disorder), absence of degenerative neurological pathologies and ability to understand and want to participate in the research), the first practical phase of the research was carried out with the execution of the clinical interview, asking the participants to omit any information (at this stage) about the previous psychopathological diagnosis suffered, so as not to induce the writer into any conditioning.

The second phases of the research concluded with the initialling and interpretation, in the telematic presence with the interviewed subject, of the PICI-1 clinical interview (TA version) and MMPI-II.

The third phases of the research concluded with the administration of PSM-1 and its interpretation of the final questionnaire.

The last phase of the research, the fourth, ended with an informative comparison between the results of the simple clinical interview with the results of PICI-1TA and PSM-1, noting the following:

1) The MMPI-II identifies some characteristics that can lead us back to the paraphiliac disorder and to other annexed personality disorders but it does not specify in detail the paraphiliac universe of the patient and therefore the exact therapeutic intervention to be carried out.
2) The PICI-1TA fully absorbs the result of the MMPI-II and notes its critical aspects, such as the absence of the indications of the specific personality traits, useful in the diagnostic and therapeutic phase, without however listing in detail the paraphiliac universe of the patient.

3) The PSM-1, associated to the PICI-1TA, allows to identify the primary disorder, the secondary characterising traits and the whole paraphiliac universe of the patient, for the purposes of the clinical diagnostic profile and of the specific targeted therapeutic intervention to be carried out, giving also information about the medical history and other possible associated sexual disorders. In addition, the PSM-1was able to detect 27 (16 male and 11 female) diagnostic errors (22.13\%) during the patient's centring phase, thus downgrading the diagnosis of paraphiliac disorder to a simple paraphilia to be managed in a more judgment-free framework:

\begin{tabular}{|c|c|c|c|}
\hline $\begin{array}{c}\text { Gender of the sample } \\
\text { Population }\end{array}$ & Bunds of age & $\begin{array}{c}\text { Sample } \\
\text { number }\end{array}$ & $\begin{array}{c}\text { Error rate of the previous } \\
\text { one } \\
\text { Diagnostic }\end{array}$ \\
\hline Male & $14-24$ & 4 & $14,8 \%$ \\
\hline Male & $25-35$ & 7 & $25,9 \%$ \\
\hline Male & $36-46$ & 3 & $11,10 \%$ \\
\hline Male & $47-57$ & 2 & $7,4 \%$ \\
\hline Male & $58-68$ & 0 & 0 \\
\hline Male & $69-79$ & 0 & 0 \\
\hline Female & $14-24$ & 4 & $14,8 \%$ \\
\hline Female & $25-35$ & 6 & $22,2 \%$ \\
\hline Female & $36-46$ & 1 & $3,7 \%$ \\
\hline Female & $47-57$ & 0 & 0 \\
\hline Female & $58-68$ & 0 & 0 \\
\hline Female & $69-79$ & 0 & 0 \\
\hline
\end{tabular}

4) The PSM-1 (Sections A-B-C-D), unlike other psychosexual tests and questionnaires, allows the following aspects to be analysed at the same time, with precision:

a) personal and family psychophysical history;

b) information about orientation, gender and related sexual disorders;

c) the paraphiliac universe, with specific indications of the object/content of individual behaviours;

d) the psychodynamic profile of the patient, on the basis of his disorder (if present) or of the simple behavioural manifestation of a paraphiliac matrix

e) the categorisation by intensity, severity and content.

The present research work has therefore demonstrated the reliability of the psychodiagnostic instrument, also noting that the highest percentage of diagnostic errors in the area of sexual behaviour is present in both males and females in the 25-35 age group, followed by the 14-24 age group, for an overall total of $40.7 \%$ in males and $37 \%$ in females. It would appear that diagnostic errors are less frequent in the older and more mature age groups. 


\section{The limits of this research are}

1. the use of a population sample that is not sufficiently representative, although the result of $40.7 \%$ in men and $37 \%$ in women suggests a good reliability of the psychodiagnostic instrument if applied to a larger sample of the population.

2. PICI-1 consists of two clinical interviews, based on the age of the interviewed subject; however, the one referring to the child and pre-adolescent age cannot be used in relation to MMPI-II because the theoretical assumption, the reference model and the nosography used are different. The present research work is therefore aimed at studying the reliability of PICI-1TA only (adolescents and adults). Therefore, the PSM-1 can also be calibrated, for the purpose of the reliability study, only on the PICI-1TA.

3. The PICI-1 and PSM-1 are not yet standardised psychometric instruments but are proposed, despite the excellent results obtained and already published in international scientific journals $[43,44,53]$

4. As PSM-1 is a free psychodiagnostic tool, this research has no financial backer and does not present any conflicts of interest.

\section{Conclusions}

The present research work has laid the foundations for a more accurate and detailed investigation of the diagnostic universe linked to paraphiliac disorder, demonstrating that:

1) At the diagnostic stage, it is always possible to commit an interpretative error by mistaking a simple paraphilia for paraphiliac disorder, also taking into account the psychological disorders present in comorbidity [54-63].

2) The MMPI-II identifies some characteristics that can be traced back to paraphiliac disorder and other related personality disorders but does not specify in detail the paraphiliac universe of the patient and therefore the exact therapeutic intervention to be carried out in psychotherapy $[64,65]$.

3) The PICI-1TA fully absorbs the results of the MMPI-II and notes its critical aspects, such as the absence of the indications of the specific personality traits, useful in the diagnostic and therapeutic phases, without however listing in detail the paraphiliac universe of the patient.

4) The PSM-1 (the specially constructed questionnaire on relevant sexual behaviours), if associated with the PICI-1TA, allows to identify the primary disorder, the characterizing secondary traits and the whole paraphiliac universe of the patient, for the purposes of the clinical diagnostic profile and of the specific targeted therapeutic intervention to be carried out, giving also information about the medical history and other possible associated sexual disorders.
5) The PSM-1 was able to detect, on a sample of population n. 122 , n. 27 (16 male and 11 female) diagnostic errors $(22.13 \%)$ in the phase of centering of the patient, depowering the diagnosis of paraphiliac disorder to simple paraphilia to be managed in a framework more deprived of judgment.

6) The PSM-1, unlike other psychosexual tests and questionnaires, allows to analyse at the same time with precision the following aspects

a) personal and family psychophysical history;

b) information about orientation, gender and related sexual disorders;

c) the paraphiliac universe, with specific indications of the object/content of individual behaviours;

d) the psychodynamic profile of the patient, on the basis of his disorder (if present) or of the simple behavioural manifestation of a paraphiliac matrix;

e) categorisation by intensity, severity and content.

7) The present research work has therefore demonstrated the reliability of the psychodiagnostic instrument, also noting that the highest percentage of diagnostic error on the subject of sexual behaviour is present in both males and females in the 25-35 age band, followed by the 1424 age band, for an overall total of $40.7 \%$ in males and $37 \%$ in females. It would appear that diagnostic errors are less frequent in the older and more mature age groups.

\section{References}

1. Perrotta G (2019) Psicologia clinica. Luxco Ed., 1st ed.

2. Perrotta G (2019) Psicologia generale. Luxco Ed., 1th ed.

3. Perrotta G (2019) Psicologia dinamica. Luxco Ed., 1th ed.

4. Perrotta G (2019) The reality plan and the subjective construction of one's perception: the strategic theoretical model among sensations, perceptions, defence mechanisms, needs, personal constructs, beliefs system, socia influences and systematic errors. J Clinical Research and Reports 1. Link: https://bit.ly/3b34baH

5. Perrotta G (2019) Obsessive-Compulsive Disorder: definition, contexts, neural correlates and clinical strategies. Cientific Journal of Neurology 1: 08-16. Link: https://bit.ly/3pxNbNu

6. Perrotta G (2019) Delusions, paranoia and hallucinations: definitions, differences, clinical contexts and therapeutic approaches. Cientific Journal of Neurology (CJNE) 1: 22-28.

7. Perrotta G (2020) Psychotic spectrum disorders: definitions, classifications, neural correlates and clinical profiles. Ann Psychiatry Treatm 4: 070-084. Link: Link: https://bit.ly/2QI9kNc

8. Perrotta G (2021) The state of consciousness: from perceptual alterations to dissociative forms. Defining, neurobiological and clinical profiles. J Neuro Neurol Sci Disord 7: 006-018. Link: https://bit.ly/2P9JVvf

9. Perrotta G (2019) Bipolar disorder: definition, differential diagnosis, clinical contexts and therapeutic approaches. J Neuroscience and Neurological Surgery 5. Link: https://bit.ly/34SoC67 
10. Perrotta G (2020) Borderline Personality Disorder: definition, differential diagnosis, clinical contexts and therapeutic approaches. Ann Psychiatry Treatm 4: 043-056. Link: https://bit.ly/3hx2B1N

11. Perrotta G (2020) Narcissism and psychopathological profiles: definitions, clinical contexts, neurobiological aspects and clinical treatments. J Clin Cases Rep 4: 12-25

12. Perrotta G (2020) Human mechanisms of psychological defence: definition, historical and psychodynamic contexts, classifications and clinical profiles. Int J Neurorehabilitation Eng 7: 1. Link: https://bit.ly/2L0I5dJ

13. Freud S (1976) Pulsioni e loro destini, OSF. Boringhieri, Torino 8.

14. Freud S (1976) L'inconscio, OSF, Boringhieri, Torino 8.

15. Genovese C (1995) La fantasia-realtà nella dimensione proto-mentale. in Ammaniti M. e Stern D.N. (a cura di), Fantasia e realtà nelle relazioni interpersonali, Laterza, Bari.

16. Hinshelwood RD (1989) A Dictionary of Kleinian Thought. Free Association Books (trad. it. Dizionario di psicoanalisi kleiniana, Cortina, Milano).

17. Isaacs S (1948) The nature and function of phantasy. Int J Psycho Anal 29 73-97. Link: https://bit.ly/3gF3YLN

18. Laplance J, Pontalis JB (1967) Vocabulaire de la psychanalyse, Presses Universitaires de France, Paris

19. Sandler J, Nagera H (1963) Aspects of the Metapsychology of Fantasy Psychoanal Study Child 18: 159-194. Link: https://bit.ly/3xmhPxg

20. Segal H (1964) Introduction to the Work of Melanie Klein, The Hogart Prese Ltd, London.

21. Segai H (1991) Dream, Phantasy and Art, Routledge, London.

22. Petrelli D (1995) Famiglia e separazione tra vicende reali e fantasmatiche. Interazioni, n. 6, pcf, Società italiana di psicanalisi della coppia e della famiglia.

23. Leitenberg H, Henning K (1995) Sexual Fantasy. Psychological Bulletin 117 Link: https://bit.ly/3pYY8Jy

24. Heiman JR (1977) A Psychophysiological Exploration of Sexual Arousa Patterns in Females and Males. Psychophysiology 14: 266-274. Link: https://bit.ly/3iMz5Yt

25. Hsu B, Kling A, Kessler C, Knapke K, Diefenbach P, et al. (1994) Gende Differences in Sexual Fantasy and Behavior in a College Population: A TenYear Replication. J Sex Marital Ther 20: 103-118. Link: https://bit.ly/3gCsTzL

26. Perrotta G (2020) Dysfunctional attachment and psychopathological outcomes in childhood and adulthood. Open J Trauma 4: 012-021. Link: https://bit.ly/2Mi2ThB

27. Goleman D, Stoller RJ (1991) Teacher And Leading Sex-Identity Theorist. The New York Times.

28. Petruccelli F, Simonelli C, Vizzari V (2009) Le perversioni sessuali. Aspetti clinici e giuridici del comportamento sessuale deviante, Franco Angeli ed.

\section{APA (2013) DSM-V, Washington, USA.}

30. Perrotta G (2019) Behavioral addiction disorder: definition, classifications, clinical contexts, neural correlates and clinical strategies. J Addi Adol Beh 2 Link: https://bit.ly/3rAT9ip

31. Kandel ER at al (2017) Principi di Neuroscienze, Casa Editrice Ambrosiana

32. Archer J, Graham-Kevan N, Davies M (2005) Testosterone and aggression: a reanalysis of Book, Starzyk, and Quinsey's study. Aggress Violent Behav 10: 241-261. Link: https://bit.ly/2SEivzr

33. Gargiullo BC, Damiani R (2018) Basi neurobiologiche del comportamento sessuale perverso, Franco Angeli, Milano.
34. Gargiullo BC, Damiani R. (2008) Il crimine sessuale tra disfunzioni e perversioni, Franco Angeli, Milano.

35. Raine A, Meloy JR, Bihrle S, Stoddard J, La Casse L, et al. (1998) Reduced prefrontal and increased subcortical brain functioning assessed using positron emission tomography in predatory and affective murderers. Behav Sci Law 16: 319-332. Link: https://bit.ly/3vA9THv

36. Perrotta G (2019) Paraphilic disorder: definition, contexts and clinical strategies. J Neuro Research 1: 4. Link: https://bit.ly/3gxr1t3

37. Perrotta G (2020) Dysfunctional sexual behaviors: definition, clinical contexts neurobiological profiles and treatments. Int J Sex Reprod Health Care 3: 061 069. Link: https://bit.ly/3hxT4aU

38. Quattrini F (2015) Parafilie e Devianza. Psicologia e Psicopatologia del Comportamento Sessuale Atipico, Firenze, Giunti ed.

39. Jannini EA, Lenzi A, Maggi MA (2007) Sessuologia medica. Trattato di psicosessuologia e medicina della sessualità, Milano, Elsevier ed.

40. Perrotta G (2021) Maladaptive stress: Theoretical, neurobiological and clinical profiles. Arch Depress Anxiety 7: 001-007. Link: https://bit.ly/3sDs39Y

41. Perrotta G (2019) Anxiety disorders: definitions, contexts, neural correlates and strategic therapy. J Neur Neurosci 6: 046. Link: https://bit.ly/2WSmiaT

42. Perrotta G (2020) Perrotta Integrative Clinical Interview

43. Perrotta G (2020) The structural and functional concepts of personality: The new Integrative Psychodynamic Model (IPM), the new Psychodiagnostic Investigation Model (PIM) and the two clinical interviews for the analysis of personality disorders (Perrotta Integrative Clinical Interview or PICI) for adults and teenagers (1TA version) and children (1C version), Psychiatry Peertechz E-book. Link: https://bit.ly/2SqQevV

44. Perrotta G (2020) "Perrotta Integrative Clinical Interview (PICl-1)" Psychodiagnostic evidence and clinical profiles in relation to the MMPI-II, Ann Psychiatry Treatm 4: 062-069. Link: https://bit.ly/3q0bYLP

45. Perrotta G (2020) Pedophilia: definition, classifications, criminological and neurobiological profiles and clinical treatments. A complete review. Open $J$ Pediatr Child Health 5: 019-026. Link: https://bit.ly/38Jzggz

46. Perrotta G (2020) Gender dysphoria: definitions, classifications, neurobiological profiles and clinical treatments. Int J Sex Reprod Health Care 3: 042-050. Link: https://bit.ly/3vssyFf

47. Perrotta G (2021) Etiological factors and comorbidities associated with the "Gender Dysphoria": Definition, clinical contexts, differential diagnosis and clinical treatments. Int J Sex Reprod Health Care 4: 001-005. Link: https://bit.ly/3gCt8uF

48. Perrotta G (2020) Cuckolding and Troilism: definitions, relational and clinical contexts, emotional and sexual aspects and neurobiological profiles. A complete review and investigation into the borderline forms of the relationship: Open Couples, Polygamy, Polyamory. Annals of Psychiatry and Treatment Ann Psychiatry Treatm 4: 037-042. Link: https://bit.ly/2TFODD3

49. Perrotta G (2020) Sexual orientations: a critical review of psychological clinical and neurobiological profiles. Clinical hypothesis of homosexual and bisexual positions. Int J Sex Reprod Health Care 3: 027-041. Link: https://bit.ly/38DtEVa

50. Perrotta G (2020) Bisexuality: definition, humanistic profiles, neural correlates and clinical hypotheses. J Neuroscience and Neurological Surgery 6. Link: https://bit.ly/2L6VXmA

51. Perrotta G (2020) Neonatal and infantile abuse in a family setting. Open $J$ Pediatr Child Health 5: 034-042. Link: https://bit.ly/2KApVQo

52. Perrotta G (2020) Psychological trauma: definition, clinical contexts, neura correlations and therapeutic approaches. Curr Res Psychiatry Brain Disord: CRPBD-100006. Link: https://bit.ly/37UD3bz

Citation: Perrotta G (2021) Sexual fantasies: The boundary between physiology and psychopathology. Clinical evidence. Int J Sex Reprod Health Care 4(1): 042-052. DOI: https://dx.doi.org/10.17352/ijsrhc. 000023 
53. Perrotta G (2021) Perrotta Individual Sexual Matrix Questionnaire (PSM1). The new clinical questionnaire to investigate the main areas of the individual sexual matrix. Int J Sex Reprod Health Care 4: 013-021. Link: https://bit.ly/3oTua9o

54. Perrotta G (2019) Neural correlates in eating disorders: Definition, contexts and clinical strategies. J Pub Health Catalog 2: 137-148. Link: https://bit.ly/3mWmf8s

55. Perrotta G (2019) Post-traumatic stress disorder: Definition, contexts, neural correlations and cognitive-behavioral therapy. J Pub Health Catalog 2: 40-47. Link: https://bit.ly/3rvaCc6

56. Perrotta G (2019) Sleep-wake disorders: Definition, contexts and neural correlations. J Neurol Psychol 7: 09. Link: https://bit.ly/3hoBiGO

57. Perrotta G (2019) Depressive disorders: Definitions, contexts, differential diagnosis, neural correlates and clinical strategies. Arch Depress Anxiety 5 009-033. Link: https://bit.ly/2KADvDm

58. Perrotta G (2019) Panic disorder: definitions, contexts, neural correlates and clinical strategies. Current Trends in Clinical \& Medical Sciences 1. Link: https://bit.ly/38IG6D5
59. Perrotta G (2019) Attention Deficit Hyperactivity Disorder: definition, contexts, neural correlates and clinical strategies. J Addi Adol Behav 2. Link: https://bit.ly/3aQyWiU

60. Perrotta G (2019) Specific learning and language disorders: definitions, differences, clinical contexts and therapeutic approaches. J Addi Adol Behav 2. Link: https://bit.ly/2Jqx7h9

61. Perrotta G (2019) Tic disorder: definition, clinical contexts, differential diagnosis, neural correlates and therapeutic approaches. J Neurosci Rehab 1-6. Link: https://bit.ly/3rEagQm

62. Perrotta G (2020) Suicidal risk: definition, contexts, differential diagnosis, neural correlates and clinical strategies. J Neuroscience Neurological Surgery 6: 114. Link: https://bit.ly/3aMqcu5

63. Perrotta G (2020) Pathological gambling in adolescents and adults: definition clinical contexts, differential diagnosis, neural correlates and therapeutic approaches. ES J Neurol 1: 1004. Link: https://bit.ly/34RmUlj

64. Perrotta G (2020) Accepting "change" in psychotherapy: from consciousness to awareness. Journal of Addiction Research and Adolescent Behaviour 3.

65. Perrotta G (2020) The strategic clinical model in psychotherapy: theoretical and practical profiles. J Addi Adol Behav 3: 5. Link: https://bit.ly/3aPMx9X
Discover a bigger Impact and Visibility of your article publication with

\section{Peertechz Publications}

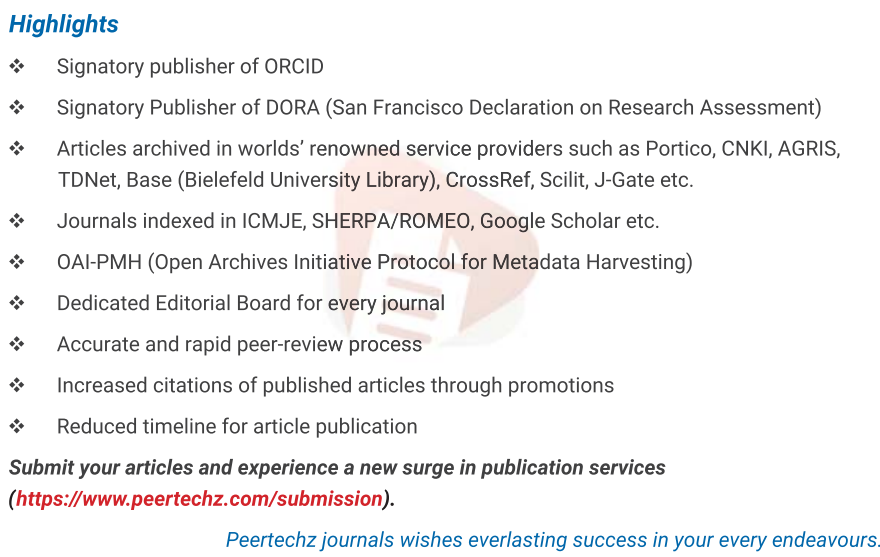

Copyright: () 2021 Perrotta G. This is an open-access article distributed under the terms of the Creative Commons Attribution License, which permits unrestricted use, distribution, and reproduction in any medium, provided the original author and source are credited. 